\title{
LIMITES E POSSIBILIDADES DA POLÍTICA DE DESENVOLVIMENTO TERRITORIAL: UMA ANÁLISE A PARTIR DO TERRITÓRIO CENTRAL DA CIDADANIA DO
} RS

\section{LIMITS AND POSSIBILITIES OF THE TERRITORIAL DEVELOPMENT POLICY: AN ANALYSIS FROM THE TERRITORY CITIZENSHIP CENTRAL OF RS}

\author{
Tatiana Aparecida Balem \\ Instituto de Educação, Ciência e Tecnologia Farroupilha/campus Júlio de \\ Castilhos - Julio de Castilhos - RS - Brasil \\ Gustavo Pinto da Silva \\ Universidade Federal de Santa Maria - Santa Maria - RS - Brasil \\ José Marcos Froehlich \\ Universidade Federal de Santa Maria - Santa Maria - RS - Brasil
}

\begin{abstract}
Resumo: O Programa Territórios da Cidadania, criado em 2008 em substituição ao Programa Territórios Rurais de 2003, destaca-se como a política de desenvolvimento territorial brasileira. Este trabalho tem por objetivo, a partir da análise do Território da Cidadania Central do Rio Grande do Sul, identificar se os limites e as possibilidades da implantação deste território são oriundos da política pública ou das particularidades da própria região. Foram delimitadas quatro chaves analíticas para análise, as quais buscam discutir como a política vem sendo implantada e como a noção de desenvolvimento territorial vem sendo apropriada pela sociedade. Além disso, buscase apresentar os principais limites para o desenvolvimento da política territorial. Mesmo que o território se mostre um importante espaço de discussão e de mobilização da região, ainda se mostra insuficiente para dar conta do desenvolvimento territorial, já que as ações políticas e de desenvolvimento para o espaço circunscrito no mesmo não convergem totalmente.
\end{abstract}

Palavras-chave: Desenvolvimento territorial. Política pública. Território da Cidadania. 
Abstract: The Citizenship Territories Program, created in 2008 to replace the Rural Areas Program 2003, stands out as the Brazilian territorial development policy. This work aims, from the analysis of the Central Territory Citizenship of Rio Grande do Sul, to identify if the limits and possibilities of implementation of this territory are from public policy or from particularities of the region itself. Were outlined four keys for analytical analysis, which seek to discuss how policy has been implemented and how the notion of territorial development has been appropriated by society. In addition, we seek to present the main limitations for the development of territorial politics. Even if the territory proves an important forum for discussion and mobilization in the region, yet is insufficient to account for the territorial development, since the actions and policies of development for the circumscribed space not fully converge.

Keywords: Public policy. Territory of the Citizenship. Territorial development.

\section{Introdução}

As teorias de desenvolvimento evoluíram e geraram novos enfoques, sendo que o enfoque territorial rompe com a ótica do desenvolvimento como um processo homogêneo e passível de ser reproduzido em qualquer realidade. Segundo Jimenéz (2002), o reconhecimento de que a produção de um país tende a concentrar-se mais em determinadas regiões mostra que os fatores endógenos territoriais estão relacionados ao desenvolvimento. Assim, os aspectos territoriais e a geografia têm se convertido em referências fundamentais dos processos socioeconômicos, num paradoxo entre a globalização (em que as distâncias estariam se banalizando) e a dimensão territorial.

A crise do regime de acumulação fordista e o advento da acumulação flexível ou pós-fordismo levam a discussão do desenvolvimento para o enfoque do território, em que a localidade converte-se em suporte de uma sociedade composta por atores que se relacionam, que possuem capacidade de atuação frente aos problemas, que contam com recursos e podem e devem participar em seu próprio desenvolvimento (JIMENEZ, 2000; GUERRERO, 1995). Esse desenvolvimento, por ser gestado de dentro para fora, por estar de acordo com as capacidades instaladas num determinado espaço geográfico e por respeitar os recursos existentes (sejam eles materiais ou não), diferencia-se de um território para outro, criando identidades próprias na noção de desenvolvimento. 
O Brasil, seguindo experiências de outros países ${ }^{1}$, tem desenvolvido algumas iniciativas em favor da promoção de uma política pública voltada para o desenvolvimento territorial. Atualmente, o principal programa existente denomina-se Territórios da Cidadania, estabelecido em 2008 em sucessão ao Programa de Territórios Rurais de Identidade, existente desde 2003. A realização dessa política tem imposto uma série de desafios, visando à promoção de uma gestão participativa do desenvolvimento sustentável dos territórios rurais e à promoção, à implementação e à integração de políticas públicas.

Mesmo que se considere a importância desse espaço de articulação e a construção de uma visão de desenvolvimento, alguns questionamentos podem ser realizados com relação à política pública. Entre as principais questões, está a própria compreensão do território, ora visto como produto das interações entre atores protagonistas ora visto como uma arena passiva, depositário de políticas definidas e descentralizadas pelo Estado. As mudanças que estão acontecendo decorrem da política de Territórios pensada e gestada desde o Estado ou são decorrentes do próprio território e de sua riqueza material e humana.

Cazella e Búrigo (2008), ao analisarem uma experiência de implementação da política de desenvolvimento territorial brasileira, avaliam que esta pouco tem avançado no sentido de instaurar processos de desenvolvimento territorial. Isso se deve, principalmente, ao agrupamento de municípios, que representariam um território muito mais pela lógica distributiva de recursos do que pela identificação de recursos e ativos presentes em determinado espaço (IBIDEM). Outra questão discutida pelos autores é que a conformação dos territórios, muitas vezes, não considera e não catalisa experiências de planejamento regional em andamento. Da mesma forma, a organização com o fim principal de captar recursos não favorece a cooperação intermunicipal, o planejamento regional, a discussão do significado teórico metodológico do desenvolvimento territorial e o exercício de parcerias intersetoriais.

Nesse contexto, este trabalho propõe analisar, a partir do Território da Cidadania Central do Estado do Rio Grande do Sul, se os

\footnotetext{
1 Cazella (2011) faz uma sinopse dos antecedentes de políticas desse tipo no Brasil e no mundo.
} 
condicionantes dos limites e das possibilidades da implantação desse território são oriundos da política pública ou relacionam-se a peculiaridades da própria região.

Para obter as respostas, buscou-se suporte em uma abordagem qualitativa, baseada em entrevista ao articulador territorial, em pesquisa documental e bibliográfica em documentos, leis e regulamentos, assim como na observação realizada da participação efetiva de um dos autores como membro do colegiado do Território da Cidadania Central. A análise foi desenvolvida a partir da construção de significados em torno do conteúdo das mensagens, fazendo confrontações com a bibliografia existente sobre o tema.

O trabalho organiza-se em cinco seções, sendo que a primeira é esta que introduz a discussão. A segunda seção apresenta o conceito de desenvolvimento territorial utilizado pelos autores, conceito que guia a interpretação do impacto da ação da política territorial do governo federal no Território Central do RS. A terceira seção descreve, de forma breve, a evolução da política de desenvolvimento territorial brasileira e situa o território Central do Rio Grande do Sul, objeto de análise deste artigo. A quarta seção busca apresentar como se desdobrou a política territorial no Território Central, sendo que, para isso, foram eleitas algumas categorias de análise, com o intuito de estabelecer condições de generalizações para essa discussão, quais sejam: estrutura do território; capacidades instaladas no território; animação social e articulação; espaços institucionais e complementariedades de políticas públicas; e limitações do programa Territórios da Cidadania como política pública. A quinta seção mostra algumas considerações finais que apontam, de forma generalizada, os principais resultados da reflexão deste artigo e da região delimitada por um território, assim como reflexões sobre a política territorial.

\section{0 conceito de desenvolvimento territorial}

O desenvolvimento territorial parte do princípio de que é necessário mobilizar e organizar os recursos existentes em um dado território. Segundo Guerrero (1995), território é uma localidade que se converte de um lugar como outro qualquer a um lugar que sustenta uma sociedade composta por atores sociais. Tais atores, segundo o 
autor, são capazes de refletir sobre seus processos, tomar decisões e promover o seu próprio desenvolvimento, a partir dos recursos circunscritos nesse território, sejam eles naturais, sociais ou culturais.

Território é proximidade, atores e interações (REIS, 2005). Logo, de acordo com essa concepção, o desenvolvimento não é um processo homogêneo e de acordo com um modelo, pois reconhece-se que os recursos são diferentes e cambiantes de um território para outro. A noção de desenvolvimento territorial, desde baixo, ressalta 0 protagonismo que deve corresponder aos agentes da comunidade, sendo que o desenvolvimento endógeno aponta para a mobilização dos recursos disponíveis na comunidade (GUERRERO, 1995).

A globalização, que cria no imaginário um só mundo e um só lugar, é contestada com a concepção de desenvolvimento territorial. Conforme Harvey (2011), é necessário compreender a globalização como um processo que ocorreu e que ainda está ocorrendo, pois o desenvolvimento capitalista recorre à reorganização geográfica como solução parcial para suas crises, desconstruindo e reconfigurando, a fim de abrir caminho para uma acumulação maior que o estágio anterior. Assim, mesmo que se busque um só mundo, vive-se em espaços desiguais: "O exame do mundo em qualquer escala particular revela de imediato toda uma série de efeitos e processos que produzem diferenças geográficas nos modos de vida, nos padrões de vida, nos usos de recursos, nas relações com o ambiente e nas formas políticas e culturais" (HARVEY, 2011 , p. 110).

Considerando o exposto pelo autor, parece ilógico insistir no modelo de desenvolvimento sinônimo de crescimento econômico, porém é preciso considerar que as diferenças geográficas e sociogeográficas também foram produzidas e são legados de outros ciclos de atividade. Assim, para a discussão de desenvolvimento territorial, deve-se considerar que muito do resultado de determinados territórios é condicionado por um histórico de ocupação ou de exploração de uma sociedade sobre outras.

Cada território é um lugar próprio, detentor de um papel e de significados próprios, não apenas complementares e, muito menos, derivados de determinações com as quais estabeleça uma relação hierárquica dependente e sucessiva (REIS, 2005). Desse modo, é resultado da interação de três dimensões: duas que formam a rede 
matricial interna (proximidade e densidade), e uma relacionada às estruturas de poder em que os territórios estão imersos e à forma que o território se inscreve no mapa territorial do mundo (polimorfismo estrutural). A proximidade está relacionada à consolidação de culturas, práticas e instituições, representando um conjunto de circunstâncias, capazes de desencadear a formação de densidades, as quais exprimem as interações continuadas, estabelecem a coordenação dos atores sociais em multiplicação ou definhamento de contextos institucionais e de governança (REIS, 2005). O polimorfismo estrutural refere-se à capacidade de o território expressar diferenciações dentro de ordens mais vastas, contemplando o poder que ele incorpora, as inter-relações e os atores que o formam, as iniciativas que ele gera e as transformações a que ele obriga (REIS, 2005). Trata-se de uma tensão e ajuste entre mobilidades (características dos fatores produtivos e dos atores que não estão presos em condições territoriais concretas) e territorializações (valorizações em contextos espaciais de recursos, capacidades, atores e condições).

Sumpsi (2007) salienta que, ao pensar o desenvolvimento territorial, há a necessidade de analisar questões como: as condições efetivas dos territórios, ou seja, os recursos existentes neles, sejam sociais, culturais, naturais ou produtivos, e a aproximação que esses recursos possuem dentro do espaço geográfico; as condições institucionais, se as instituições realmente estão preparadas para promover um desenvolvimento endógeno e desde baixo; as condições produtivas capazes de possibilitar o desenvolvimento econômico; e os programas de desenvolvimento planejados, especificamente, para que se mobilizem os recursos existentes, as instituições e os fatores produtivos, para a promoção desenvolvimento territorial.

Traçando um paralelo entre a discussão de Harvey (2011), que afirma que os espaços geográficos são histórica e socialmente construídos, e com o que aponta Reis (2005) e Sumpsi (2007) para o desenvolvimento territorial, pode-se dizer que alguns territórios precisam ser mais mobilizados que outros, pois as situações concretas para a ativação do desenvolvimento são diferentes. Essa é uma questão fundamental ao delimitar ou traçar os territórios, ou seja, definir exatamente quais características aproximam os componentes de um determinado espaço e quais afastam, para que a proposta de 
desenvolvimento territorial realmente encontre elos entre as condições naturais e produtivas, com as culturais e sociais dos espaços.

Segundo Sumpsi (2007), as políticas de desenvolvimento, quando definidas para um território, devem buscar assegurar a equidade social, aumentar a participação política, promover a eficiência e a transparência das administrações públicas, além de buscar diversidade produtiva. A descentralização do desenvolvimento econômico empodera autoridades locais para empreender iniciativas próprias de impulso de suas economias, porém estas devem ser capazes de mobilizar todos os recursos necessários para que isso ocorra. O local aqui mencionado está relacionado aos municípios, pois, no caso brasileiro, eles são a menor unidade de federação e, embora a política de desenvolvimento territorial vise construir estratégias de desenvolvimento pactuadas no território, a ação final acaba sendo definida no âmbito do município.

Para Guerreiro (1995), o processo ideal de desenvolvimento deveria nascer das realidades locais e ir irradiando-se conforme as habilidades dessas realidades de mobilizarem os recursos e ativos territoriais, apontados por Pecqueur (2005) como genéricos e específicos. No entanto, como afirma Cazella e Búrigo (2008), é necessário considerar todos os setores presentes no território e promover ações de desenvolvimento intersetoriais, sob pena de, mesmo sob a retórica do desenvolvimento territorial, trabalhar-se com setores específicos e de forma isolada. O que, novamente, traz ao cenário a discussão de local e territorial, pois o local estaria na jurisdição do município, e o territorial, no ajuste e na busca de sinergias no âmbito de um conjunto de municípios. O que acontece é que, nos espaços de discussão do território, no Brasil, as ações são discutidas por um colegiado territorial, mas as ações são demandadas e implementadas via município.

No Brasil, de acordo com Delgado e Leite (2011, p. 431), a discussão de desenvolvimento territorial deu-se com a "observação da persistência interligada da pobreza rural e da desigualdade social e regional, e enquadra-se na discussão mais ampla sobre o desenvolvimento econômico e a sustentabilidade". Como o território é uma arena de disputas e de concertação entre os atores sociais, esperase que as estratégias de desenvolvimento territorial encontrem obstáculos. Por outro lado, o território não é uma noção para 
compreender somente o rural, mas para estudar todas as relações existentes em um determinado espaço sociogeográfico. Assim, o rural e o urbano, as relações entre estes e os recursos e ativos são partes configurantes do território.

Ainda segundo Delgado e Leite (2011), as ações dos programas governamentais de fomento a essas estratégias devem ser pactuadas com as arenas decisórias e os espaços públicos, para que seja possível o empoderamento dos diversos atores e agências institucionais presentes nesses espaços. Essas questões refletirão no desenho de projetos estratégicos e definidos numa escala que ultrapassa o local ou a jurisdição do município. O grande ponto da questão parece estar na possibilidade da política pública conduzir estratégias que mobilizem os recursos e ativos dos territórios, apontados por Pecqueur (2005), e, ao mesmo tempo, fazer a pactuação de forma a empoderar os atores sociais. A dificuldade desse processo manifesta-se na baixa tradição de participação e na falta de experiência dos governos e de outros atores locais em implementar processos de desenvolvimento em escala territorial.

Assim, para a análise dos programas em prol do desenvolvimento territorial no Brasil, é necessário, segundo Delgado e Leite (2011), compreender que alguns elementos devem ser considerados para analisar o contexto das novas institucionalidades territoriais: a caracterização socioeconômica do meio rural e da estrutura de poder prevalecente; as experiências políticas, sociais e institucionais locais que precederam a criação do território e que influenciaram a sua conformação institucional; as características assumidas pela institucionalidade territorial, suas potencialidades e limites; os atores sociais participantes na institucionalidade e na gestão da política pública territorial, com destaque para a consideração dos projetos territoriais apresentados e aprovados pelo colegiado territorial; e a existência ou não de protagonismo social no território, além das características assumidas pela dinâmica institucional no mesmo. Ainda há de se considerar a necessidade de pensar o território sem 0 viés essencialmente rural, como tem acontecido na política brasileira. No entanto, por ser este o viés da política, esta análise detém-se nas ações territoriais para o rural. 
Os elementos apontados por Delgado e Leite (2011) são definidos com base na política de desenvolvimento territorial implantada, recentemente, no Brasil. Essa política, analisada na próxima seção, propõe-se a fomentar a governança local em prol de projetos de desenvolvimento territorial, mobilizando, assim, uma série de atores sociais ligados ao rural e representativos, principalmente, de setores menos impactados pelas políticas públicas, historicamente dirigidas para o rural no país.

\section{Por uma política territorial: de territórios rurais de identidade a território da cidadania}

O Estado Brasileiro tem realizado um esforço no sentido de promover a sua própria política de desenvolvimento territorial, buscando, conforme Cazella (2012), desfazer os obstáculos que resultam de sua organização vertical, ao mesmo tempo em que planeja manter-se na cena local e no plano econômico. Esse propósito em torno das dinâmicas territoriais no processo de desenvolvimento, tem alguns momentos importantes até alcançar o desenho das políticas públicas (FAVARETTO, 2010). O primeiro momento foi ainda no governo de Fernando Henrique Cardoso, quando o Programa Nacional da Agricultura Familiar - PRONAF ganhou o adjetivo Infraestrutura, visando apoiar projetos que possuíssem o caráter intermunicipal. O PRONAF Infraestrutura tinha por objetivo beneficiar municípios com alta concentração de agricultores familiares e com menos dinamismo de atividades econômicas, sendo possível a destinação de recursos para obras, equipamentos e serviços comunitários (HESPANHOL, 2006).

O segundo momento foi entre 2001 e 2002, na forma de uma série de debates preparatórios a uma conferência nacional. Já o terceiro foi em 2003, quando houve a criação da Secretaria de Desenvolvimento Territorial (SDT), no âmbito do Ministério do Desenvolvimento Agrário (MDA), que culminou com a institucionalização da política de Territórios Rurais, estabelecida no Governo Lula, em 2003, pelo decreto n. 4.854. Tal política considera "o território rural como foco do planejamento e da gestão de programas de desenvolvimento rural sustentável, a partir das inter-relações, articulações e complementaridades entre os espaços rurais e urbanos" (BRASIL, 2003). Para definir, subsidiar, propor e 
analisar as diretrizes da Política Nacional de Territórios Rurais, foi estabelecido o Conselho Nacional de Desenvolvimento Rural Sustentável - CONDRAF, órgão colegiado integrante do MDA, formado por membros do Governo e da Sociedade Civil. O CONDRAF substituiu o Conselho Nacional de Desenvolvimento Rural Sustentável, criado no ano de 2000, por meio de um conjunto de câmaras técnicas que visavam apoiar o planejamento e orientação de políticas para o setor (ECHEVERRI, 2010). Caberia à SDT secretariar o CONDRAF.

A Secretaria de Desenvolvimento Territorial do Ministério do Desenvolvimento Agrário adotou suas ações a partir do Programa de Desenvolvimento Sustentável dos Territórios Rurais, sendo o foco o combate à pobreza rural, o desenvolvimento da agricultura familiar e do público da Reforma Agrária. Nessa política, Echeverri (2010) destaca alguns aspectos-chave: integralidade das relações funcionais, econômicas e sociais entre o rural e o urbano; equilíbrio entre a visão econômica das visões mais tradicionais, com aspectos sociais, políticos e culturais; e a introdução do tema da identidade e da coesão social.

A delimitação geográfica dos territórios rurais buscou valorizar o predomínio do público prioritário do MDA (agricultores familiares, indígenas e quilombolas) e a conformação de microrregiões, conjuntamente ao perfil econômico e ambiental. Além dessa delimitação de caráter técnico, também visou uma manifestação dos atores sociais e das instâncias técnicas e políticas dos estados, buscando acordos com vistas a desvelar a identidade subjacente a cada espaço, em um processo que visava reafirmar a natureza identitária e cultural dos territórios. Por isso, essa primeira fase da estratégia foi denominada Territórios de Identidade (ECHEVERRI, 2010).

Em 25 de fevereiro de 2008, mantendo a maioria das características dos Territórios de Identidade, foi instituído, pelo governo federal, o Programa Territórios da Cidadania. A nova versão ultrapassa a visão de uma política exclusiva do MDA e compõe ações articuladas de 22 ministérios $^{2}$. Assim, o programa evoca a dimensão política da

2 O Grupo Interministerial de Execução e Acompanhamento do Programa Territórios da Cidadania foi composto por: Casa Civil, Secretaria-Geral da Presidência da República; Ministério do Planejamento, Orçamento e Gestão; Ministério do Desenvolvimento Agrário; Ministério do Meio Ambiente; Ministério da Integração Nacional; Ministério do Desenvolvimento Social e Combate à Fome; Ministério de Minas e Energia; Ministério da Saúde; Ministério da Educação; Ministério da Cultura; Ministério do Trabalho e 
cidadania (ECHEVERRI, 2010; BONNAL; DELGADO; CAZELLA, 2011), ao mesmo tempo em que representa um esforço para integrar e dar coesão a um conjunto de ações antes dispersas em diversas estruturas do poder executivo (FAVARETTO, 2010). Houve a criação dos territórios da cidadania porque o "governo entendeu que alguns territórios apresentavam-se economicamente mais fragilizados que outros e, com isso, necessitavam de uma atenção emergencial com ações ainda mais articuladas" (DELGADO; LEITE, 2011 , p. 434).

"Os Territórios da Cidadania têm como objetivos promover o desenvolvimento econômico e universalizar programas básicos de cidadania por meio de uma estratégia de desenvolvimento territorial sustentável." (BRASIL, 2008). Assim, "a participação social e a integração de ações entre Governo Federal, estados e municípios são fundamentais para a construção dessa estratégia" (BRASIL, 2008). Em relação aos Territórios de Identidade, os Territórios da Cidadania não precisam de uma posição negociada e concertada para obtenção de recursos, já que estes são descentralizados desde as instâncias governamentais de forma focalizada até os territórios designados (ECHEVERRI, 2010). O marco do programa apoia-se na superação da pobreza, na geração de trabalho e renda por meio da inclusão produtiva dos mais pobres, na integração das políticas públicas em um marco de planejamento territorial, na ampliação dos mecanismos de participação social e na universalização da oferta de programas de reconhecimento e garantia dos direitos (ECHEVERRI, 2010).

Segundo Delgado e Leite (2011), dois aspectos são centrais à lógica da ação pública para os Territórios da Cidadania: a descentralização das políticas públicas e a participação da população e o consequente empoderamento dos atores sociais. De acordo com os autores, a lógica dos territórios, adotada pelo Governo Federal, busca ultrapassar a mera soma de ações e de dotações orçamentárias sobre um mesmo espaço social. Trata-se de pensar a governança da política

Emprego; Ministério da Agricultura, Pecuária e Abastecimento; Ministério das Cidades; Ministério da Justiça; Ministério da Ciência, Tecnologia e Inovação; Ministério das Comunicações; Ministério da Fazenda; Ministério da Pesca e Aquicultura; Secretaria de Relações Institucionais; Secretaria de Políticas de Promoção da Igualdade Racial; Secretaria de Políticas para as Mulheres da Presidência da República; e Secretaria de Direitos Humanos. 
de baixo para cima, por meio de ações intersetoriais e do envolvimento dos atores sociais.

A gestão do Programa conta com: um comitê federal, que reúne os ministérios, responsável por fixar metas e orientar a formulação, a implementação, o monitoramento e a avaliação; um comitê de articulação estadual, composto por todos os órgãos federais, órgãos estaduais e representação dos prefeitos; e, localmente, com um colegiado territorial, formado por integrantes das três esferas de governo e da sociedade em cada território. O colegiado é composto por membros do poder público e da sociedade civil, com participação livre e voluntária. Segundo Echeverri (2010), o colegiado trata-se de uma instância consultiva e deliberativa, no exercício do controle social da ação pública, assim como capaz de articular a demanda com a oferta de políticas e mobilizar os processos sociais. Cada colegiado é apoiado por um assessor territorial, que representa um elo com o Governo Federal e é responsável por articular, mobilizar e facilitar o andamento das atividades.

Cada território elaborou seu Plano Territorial de Desenvolvimento Rural Sustentável - PTDRS, que deveria ser atendido por meio de descentralização de recursos, através do Programa Nacional de Desenvolvimento Sustentável dos Territórios Rurais - PRONAT. O PTDRS buscava representar a expressão da identidade territorial, contemplando um diagnóstico situacional, as prioridades e uma visão de futuro.

As ações territoriais foram planejadas em três eixos ${ }^{3}$ e sete temas ${ }^{4}$. Cada território deveria cumprir dois debates em relação à matriz de ações dispostas pelo Governo Federal e seus ministérios. O primeiro relaciona-se à importância que o colegiado territorial apresentava como órgão gestor das ações federais, considerando quatro papéis básicos: 1 - Controle social, quando somente era informada a execução de ações; 2- Consultivo, quando o Ministério recolhia sugestões junto ao território; 3- Deliberativo, quando o Ministério submetia a decisão do colegiado; 4- Articulador/mobilizador, quando o próprio colegiado identificava como poderia contribuir para que as ações acontecessem. $\mathrm{O}$

\footnotetext{
${ }^{3}$ Apoio a Atividades Produtivas, Cidadania e Infraestrutura.

${ }^{4}$ Organização Sustentável da produção; Ações Fundiárias; Educação e Cultura; Direitos

e Desenvolvimento Social; Saúde, saneamento e acesso a água; Apoio à gestão Territorial; e Infra-estrutura.
} 
segundo debate encontrava-se relacionado a vincular as matrizes dispostas em seus planos territoriais (PTDRS) com a matriz de ações propostas pelos Ministérios integrantes e disponibilizadas em matrizes territorializadas e não territorializadas. Tanto em uma forma como na outra, partia-se de uma matriz de ações propostas pelo Governo Federal em que o Território passava a ser concebido como a unidade de execução de recursos provindos da União, bem como de organização e articulação das próprias iniciativas locais.

No Rio Grande do Sul, sete territórios enquadraram-se nos critérios estabelecidos, sendo que o Território da Cidadania Central substituiu o Território Rural Central, formado por 34 municípios. Este possuía um colegiado composto por 120 integrantes, divididos em três instâncias: núcleo diretivo, núcleo técnico e plenária. Nesse ambiente, discutiam-se as diretrizes, democratizavam-se as informações, analisavam-se os projetos, programas, chamadas públicas, dentre outros. O Território da Cidadania Central possui Regimento próprio (bem como o PTDRS), elaborado em 2005, ainda enquanto Território de Identidade, e reavaliado em 2009, já como Território da Cidadania.

Desde 2005, foram aplicados em torno de $\mathrm{R} \$ 6.000 .000,00$ no Território Central, beneficiando 70 projetos, sendo que a esse valor foram acrescidos $\mathrm{R} \$ 400.000,00$ de contrapartida das prefeituras. Todos os municípios apresentaram projetos, e apenas nove não foram contemplados de forma deliberativa, mas foram-no de outras formas (Controle Social, Consultivo, Articulador e Mobilizador) por fazerem parte do programa 5 .

Na próxima seção, buscar-se-á identificar chaves analíticas que visam dar sustentação ao estudo, evidenciando, na realidade do Território Central, as características e os limitantes para o processo de promoção do desenvolvimento territorial a partir da política pública, em que pese a dos Territórios da Cidadania.

4 As possibilidades e os limites da política de territórios: uma análise a partir do Território Central da Cidadania do Rio Grande do Sul

\footnotetext{
${ }^{5}$ Informações obtidas com o Assessor Técnico Territorial do Território da Cidadania Central.
} 
O processo de construção de um território supõe harmonizar interesses conflitivos, que levem à construção de identidades, sejam políticas, econômicas ou culturais, o que acaba se configurando em um processo de construção social relativamente lento (GUANZIROLI, 2012). Assim, mais do que um recorte geográfico determinado, um território é um produto da ação humana, espaço de interação, diálogo, ajuste de projetos individuais em torno de projetos coletivos, capazes de constituir uma agenda positiva sob coordenação de uma governança local ${ }^{6}$.

A partir desses pressupostos e dialogando com vários autores, entre os quais Reis (2005), Sumpsi (2007), Cazella (2012) e Guanziroli (2012), busca-se dimensionar a existência ou não de um território constituído a partir da política pública dos Territórios da Cidadania no Centro do Estado do Rio Grande do Sul, já que foi constituído em 2005 e permanecia em atuação até 2014 . Essa discussão baseia-se em algumas questões consideradas fundamentais para o desenvolvimento territorial, distribuídas em cinco categorias de análise, que servem para orientar a interpretação dos impactos da política nesse espaço e para generalizar a discussão, quais sejam: estrutura do território; capacidades instaladas no território; animação social e articulação; e espaços institucionais e complementariedades de políticas públicas. Por último, apresentamos as limitações do programa Territórios da Cidadania como política pública.

\subsection{Estrutura do território}

O Território da Cidadania Central apresenta uma população de 652.725 habitantes, sendo que 131.520 estão estabelecidos na zona rural. Fazem parte do público direto das ações 31.965 agricultores familiares, 1.250 famílias assentadas e 11 comunidades quilombolas. Em termos de distância física, chega a $350 \mathrm{~km}$ entre os extremos do território. Neumann (2004), buscando estabelecer uma tipologia do espaço agrário, distingue três zonas fisiográficas distintas nesse espaço (Figura 01), correspondendo a paisagens agrícolas diferentes. Essas zonas distinguem-se por: uma agricultura modernizada, com destaque para a cultura da soja e do milho, mesclada com a pecuária de Corte (Zona I); uma agricultura diversificada, com predominância do fumo, da

\footnotetext{
${ }^{6}$ Nesse caso, o local refere-se à governança do território.
} 
batata inglesa, do feijão e do milho (Zona II); e uma agricultura modernizada, com destaque para o arroz, e latifúndios com a produção de gado de corte (Zona III). O mesmo autor, aprofundando a análise em busca de identificar microrregiões homogêneas, encontra seis agrupamentos com características próprias que não podem ser desconsiderados quando se discutem políticas de desenvolvimento rural adequadas para essas categorias sociais. Esses grupos revelam não somente a diversidade cultural existente, destacando-se núcleos de alemães (São Pedro do Sul, Colônia Santo Ângelo) e italianos (Quarta Colônia e Vale do Jaguari) entre a predominância de luso-brasileiros, mas também uma série de especificidades e tipos produtivos. Neumann (2004) complementa que, além da história de ocupação, também ajudam a aprofundar essas diferenças a estrutura agrária e a matriz produtiva adotada. Tal explicação pode ser evidenciada, também, no PTDRS, quando cada uma das microrregiões pôde estabelecer seus próprios interesses no quadro de demandas.

Figura 1. Zonas Fisiográficas homogêneas do Território Central

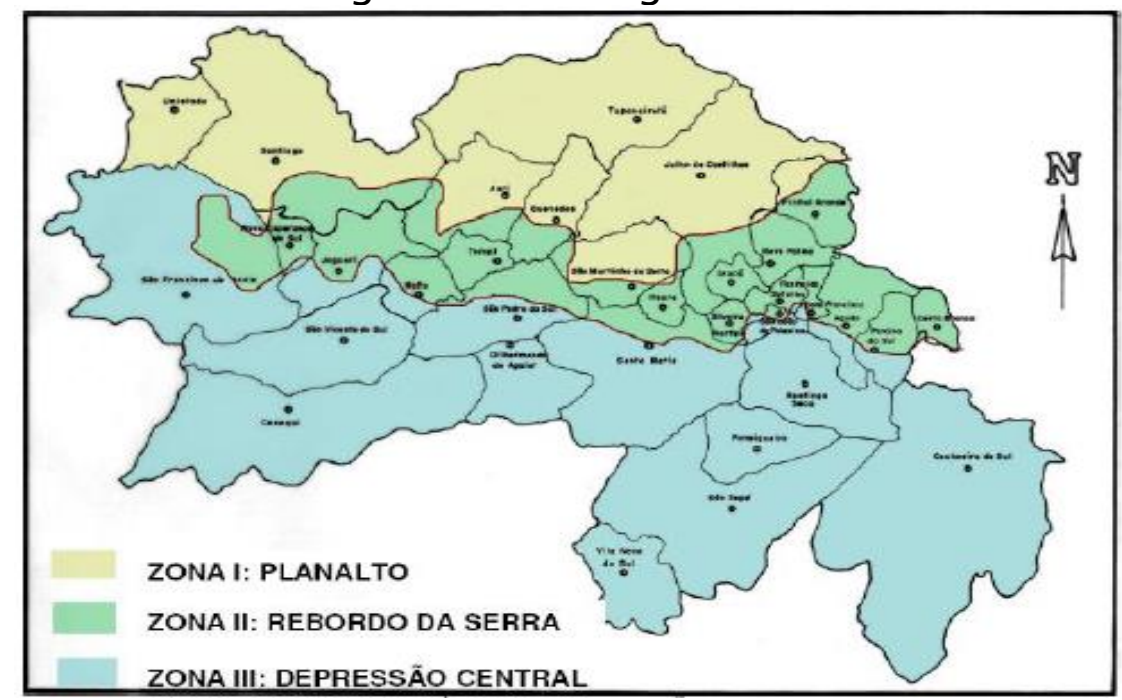

Fonte: Neumann, 2004.

A afirmação de que o território da Cidadania Central possui um conjunto de municípios com características econômicas e ambientais, identidade e coesão social, cultural e geográfica, com similaridade?,

\footnotetext{
7 De acordo com autores (REIS, 2005; ABRAVOVAY, 2007; SUMPSI, 2007), o território pode ser definido caso possua um conjunto de municípios com características econômicas e ambientais, identidade e coesão social, cultural e geográfica, com similaridade.
} 
parece-nos um equívoco diante de tamanha heterogeneidade. Cazella e Búrigo (2008), ao estudarem o território Planalto Catarinense, observam que o agrupamento de municípios não se configura em um território, o que dificultou sobremaneira que se estabelecesse de fato uma identidade territorial. No caso analisado pelos autores, o território foi definido sem considerar os ativos que poderiam configurar a identidade territorial.

Sendo os territórios resultados do que Reis (2005) denominava de interação entre os resultados da geografia (proximidade, densidade, acesso) e das culturas institucionais de governança própria, é mais difícil construir diálogos e sinergias se não está estabelecida essa relação de identificação e proximidade. Esse fato é agravado pelo debate, ainda recente, sobre a implantação da política e pela dificuldade em mobilizar a sociedade, ou seja, ainda é um debate circunscrito no alcance da política. Para o reconhecimento do território, deveriam ser identificados e considerados os recursos latentes e os ativos territoriais, no entanto a lógica distributiva de recursos financeiros parece obedecer apenas à delimitação do espaço geográfico-administrativo (CAZELLA; BúRIGO, 2008).

Diante dessas diferenças estruturais e da quantidade de municípios com realidades diferentes, torna-se mais complexo fomentar ações que realmente possam alcançar a estrutura produtiva territorial. Sumpsi (2007) alerta que uma zona muito extensa e com um grande efetivo populacional corre o risco de perder o efeito das economias de proximidade e as redes sociais que favorecem a participação, a confiança mútua e os atores locais. Se, por um lado, uma região de grande tamanho evidencia capacidade de barganha, reivindicação e uma diversidade estrutural de ativos, por outro, mostra fissuras na construção de um projeto coletivo, pois não favorece o diálogo e as circunstâncias para desencadear a formação de densidades entre os atores sociais. Ao agregar sub-regiões, a proposta do território perde em identidade social, mas ganha em barganha política (DELGADO; LEITE, 2011).

A grande questão parece ser identificar se é possível, a partir dessa diversidade, promover a construção de um território ou se são necessárias delimitações territoriais menores, conforme já evidenciado 
pela própria plenária do Território Central ${ }^{8}$. Segundo Guanziroli (2012), a negociação entre agentes e atores pode ser facilitada numa escala relativamente baixa de municípios. Em territórios menores, pressupõese que haja os fatores que Sumpsi (2007) considera fundamentais: forte identidade, entrelaçada por vínculos culturais; homogeneidade nas condições de estrutura territorial; condições produtivas; relação pela proximidade entre economias; e facilidade na comunicação, coordenada por um ajuste comum. A diversidade é importante para a mobilização de forças e atores sociais no território (HARVEY, 2011; BRANDÃO, 2007), porém não se pode cair no equívoco de, como afirma Brandão (2007), encarar o território como forma de territorializar a intervenção pública e como solução para todos os problemas de desenvolvimento. Assim, o território seria visto como repositório passivo de políticas e ações de governo, e não como um ambiente politizado, em conflito e em constante construção.

\subsection{Capacidades instaladas no território}

Os territórios podem ser considerados como uma arena de disputas entre diversos atores sociais que se inter-relacionam. De acordo com Abramovay (2007), é necessário criar redes sociais, e, para o estabelecimento destas, no desenvolvimento territorial, é necessário que a cooperação substitua a coerção como forma de regulação social. É mais fácil para a cooperação acontecer em comunidades que tenham herdado um bom estoque de capital social sob a forma de regras de reciprocidade e sistemas de participação direta (ABRAMOVAY, 2007).

No caso do Território Central, a estrutura organizacional dos municípios tende a ser mais individualista do que cooperativista, e as

8 A plenária do Colegiado Central, para melhor organização das ações, subdividiu o território em cinco microrregiões: Quarta Colônia: integrada pelos municípios de Agudo, Restinga Seca, Faxinal do Soturno, Nova Palma, São João do Polêsine, Ivorá, Silveira Martins, Pinhal Grande e Dona Francisca; Águas da Serra: integrada pelos municípios de Jari, Júlio de Castilhos, Quevedos, Itaara, São Martinho da Serra, São Pedro do Sul, Dilermando de Aguiar, Tupanciretã e Toropi; Jacuí-Centro: com os municípios de Cachoeira do Sul, Paraíso do Sul e Novo Cabrais; Vale do Jaguari: integrado por Santiago, Unistalda, Capão do Cipó, Jaguari, São Vicente do Sul, São Francisco de Assis, Cacequi, Mata e Nova Esperança do Sul; e Coração do Rio Grande/Central: composta por São Sepé, Formigueiro, Vila Nova do Sul e Santa Maria. 
aproximações têm acontecido mais por um estímulo de fora para dentro, com o movimento e interesse dos municípios em participar dos espaços coletivos instalados para captar recursos. Fato também observado por Cazella e Búrigo (2008), ao analisarem o território Planalto Catarinense, onde as prefeituras participam do espaço por entender ser mais uma oportunidade de acessar recursos do Governo Federal. Sumpsi (2007), avaliando o programa LEADER ${ }^{9}$, salienta que muitos prefeitos têm a tentação de utilizar os recursos como prolongação do orçamento municipal, dado que consideram este insuficiente. Delgado e Leite (2011), ao analisarem três territórios da Cidadania no Brasil, identificam um novo oportunismo ou um novo comportamento governamental das prefeituras, revelado pela importância e o volume de recursos anunciados pelo programa, os quais causam uma nova mobilização em torno da política territorial. Desse modo, esse tipo de recurso, facilmente, torna-se utilizado por políticos locais com fins eleitorais e de clientelismo político.

Abramovay (2007) aponta que o capital social é um dos elementos essenciais do desenvolvimento local e endógeno, pois os indivíduos não agem independentemente, e seus objetivos não são estabelecidos de maneira isolada. Os sistemas de participação cívica, costumes locais e compromissos comunitários assumidos ao longo do tempo fortalecem as relações horizontais das sociedades locais, o que tende a aumentar a cooperação e a confiança. Porém, há casos em que as raízes que formam o capital social não existem ou são demasiadamente frágeis. Nesses casos, as estratégias como mobilização dos atores locais e envolvimento dos mesmos na elaboração do projeto local, orientado ao desenvolvimento do território e realização do projeto, contribuem com a construção de um novo sujeito coletivo do desenvolvimento, que vai exprimir a capacidade de articulação entre as forças dinâmicas da região (ABRAMOVAY, 2007).

A discussão instaurada no território não considera as deficiências de muitos municípios em termos de capacidades instaladas e capital social suficiente para participar ativamente do processo. Percebe-se que

\footnotetext{
${ }^{9}$ A sigla LEADER significa Ligações Entre Ações de Desenvolvimento e Economia Rural. Trata-se de um método de mobilizar e incentivar o desenvolvimento nas comunidades rurais locais e um conjunto fixo de medidas a implementar (COMISSÃO EUROPÉIA, 2006).
} 
muitas gestões municipais acontecem com baixa mobilização social e participação da sociedade civil, voltadas, exclusivamente, para a oferta de alguns serviços básicos para a população e respaldadas pela execução de políticas estaduais ou federais. Nessas condições institucionais, é difícil discutir e considerar as bases produtivas, os recursos endógenos e o aproveitamento do histórico social e cultural construído. O debate territorial encerra-se na Plenária, e a participação dá-se de forma limitada e mecânica, sem a devida apropriação dos seus significados e sem a replicação na base.

As Plenárias aparecem como o espaço para captar recursos e, não necessariamente, por um entendimento de construção de uma convergência e sinergia de ações em benefício de um projeto coletivo e territorial. Nessas situações, entidades e organizações que, antes, não participavam do espaço de discussão do território, demandam recursos, muitas vezes, dissociados da discussão de desenvolvimento territorial. Esses projetos, normalmente, são empreendimentos requeridos por lideranças, desconexos dos interesses da comunidade e pouco relacionados ao público, que deveria ser o beneficiário do programa. Delgado e Leite (2011) identificam uma enorme fragmentação das organizações da sociedade civil local, com visões e propostas muito diversas sobre o diagnóstico, os problemas e as soluções para o território e com uma enorme desconfiança umas com as outras.

Pode-se inferir que a política de territórios ainda não foi capaz de promover o debate com os atores sociais locais do significado teóricometodológico do desenvolvimento territorial (CAZELLA; BÚRIGO, 2008). Mesmo assim, segundo Delgado e Leite (2011), essa participação, com o passar do tempo, tende a reduzir. E sem a participação, a compreensão e o envolvimento dos atores governamentais, a política não tem condições de avançar, de modo que essa presença no colegiado significa um desafio e um aprendizado indispensável para a melhoria da qualidade e da efetividade da política territorial.

A superação desse quadro é necessária para que o debate do desenvolvimento territorial seja apropriado nos municípios e a mobilização social possa atingir todos os segmentos interligados do território. Cazella (2012), revisitando outros autores, resume que, se a questão fosse apenas renda, bastaria descentralizar recursos por transferências diretas e crescimento econômico. Porém, tratando-se de 
desenvolvimento territorial, é necessária uma estratégia microrregional, regional ou territorial, elevando a consciência da comunidade sobre sua responsabilidade social. Apesar de ser básica a discussão interna nos municípios, já que muitas políticas são resolvidas dentro dessa unidade, ações territoriais são imprescindíveis não apenas na forma de projetos de produção, mas também de articulação de cadeias produtivas, construção de mercados e infraestruturas. Segundo Putnam (2003), depois que o desenvolvimento toma um determinado rumo, a cultura organizacional, os costumes e os modelos mentais do mundo social reforçam essa trajetória. E, assim, a sociedade, ao conseguir passar à solução cooperativa, tende a reforçar-se.

Entre os aspectos positivos, está o fato de o Território da Cidadania Central criar mecanismos para se proteger dos projetos que aparecem somente no momento de avaliação e que não participam das demais atividades relacionadas. Em 2010, a plenária aprovou um Edital de Seleção Pública de Propostas para Apoio a Projetos para o Desenvolvimento Sustentável da Região Central, prevendo uma série de pré-requisitos a fim de determinar as iniciativas a serem contempladas com recursos. Esse instrumento é uma medida que pode ser considerada um avanço de aprendizagem coletiva, bem como um fortalecimento do próprio Território da Cidadania enquanto organização regional de desenvolvimento.

A consolidação das estratégias de desenvolvimento com enfoque territorial requer levar adiante intensos processos de capacitação e formação dos recursos institucionais e dos atores sociais locais, bem como o desenho de instrumentos apropriados para responder às necessidades e demandas dos territórios rurais (SUMPSI, 2007). Assim, nada impede que essas capacidades não possam ser ativadas e/ou instaladas num dado território.

\subsection{Animação social e articulação}

Entre os diversos elementos fundamentais para a cooperação e a construção de uma estrutura autônoma de animação e de planejamento do desenvolvimento, no dizer de Cazella (2012), encontra-se a busca da cooperação voluntária entre os atores sociais pertencentes a um dado território. Segundo Putnam (2003), depois que a comunidade conseguir 
passar para soluções colaborativas, ela tende a romper com os círculos viciosos (desconfiança, omissão, exploração, isolamento, desordem, estagnação), tendendo à promoção de círculos virtuosos (confiança, normas, sistemas de participação). Esse é um dos desafios da promoção da política de desenvolvimento territorial, no sentido de ativar, mobilizar e transformar esses recursos dentro das comunidades, atingindo toda a diversidade de atores sociais, influenciando no funcionamento das instituições (PUTNAM, 2003).

Considerando a necessidade de mobilização e desenvolvimento do capital social, a política de desenvolvimento territorial precisa avançar na implementação de um colegiado de articuladores territoriais, com disponibilidade de tempo e de recursos. Esse é outro ponto de estrangulamento da política de Territórios da Cidadania, pois o território contava com apenas um articulador para cumprir com o papel de animação social e articulação dos municípios. O articulador ainda precisava dar conta de realizar uma série de atividades relacionadas ao funcionamento da política territorial. O colegiado do território, por sua vez, é composto por cidadãos com vínculos institucionais diversos, porém, muitas vezes, sem a qualificação necessária e dedicação exclusiva para as atividades do território, tampouco para a promoção da mobilização diretamente na base social. Seu papel acabava mais na avaliação de projetos, quando havia descentralização de recursos, ou, pontualmente, nas plenárias.

A falta de um grupo de técnicos ou agentes de desenvolvimento para atuar na mobilização dos ativos territórios e na base social do território pode ser considerada como um limitante da política. A dinamização, a mediação, a negociação, a retomada e a análise prospectiva das potencialidades territoriais são papéis inerentes à profissão do agente de desenvolvimento territorial (CAZELLA, 2012). O papel do articulador dos Territórios da Cidadania é dinamizar as informações na região, mobilizar para as plenárias e facilitar o acesso dos municípios às políticas públicas para a captação de recursos. Esse é um dos pontos positivos da política, pois o poder municipal, muitas vezes, tem dificuldade de acessar as políticas, e a articulação desempenha um papel fundamental nesse sentido.

Talvez faltem ações concertadas desde os municípios, validando mais ou complementando iniciativas do articulador, além de uma equipe 
de articuladores para dar conta de um território com tais dimensões, pois, mesmo que haja esforço, não há como um único articulador mobilizar, fazer a gestão, buscar recursos e articular projetos para todo um território tão amplo. Segundo Delgado e Leite (2011), com base no estudo de três territórios no Brasil, esse apoio administrativo, técnico e financeiro é insuficiente para dar conta de todas as tarefas envolvidas no processo de articulação territorial. Pois, como afirma Sumpsi (2007), os programas de fomento do desenvolvimento produtivo possuem requerimentos particulares quanto à assistência técnica, organizativa e outras inversões "soft", que originam gastos recorrentes (pessoal, deslocamentos, capacitação e outros) e necessitam de um tipo particular de operadores e de incentivos para o desenvolvimento dos programas, capazes de estabelecer sinergia com os beneficiários.

\subsection{Espaços institucionais e complementariedade de políticas públicas}

A diversidade de formas de organizações em termos institucionais, para construir agendas de desenvolvimento para a Região Central, apresenta fragilidades a serem vencidas. Em relação às iniciativas coletivas intermunicipais da região, destacam-se a Associação dos Municípios da Região Centro do Estado - AMCENTRO, o Consórcio de Desenvolvimento Sustentável da Quarta Colônia CONDESUS e o Consórcio Intermunicipal de Desenvolvimento Sustentável Águas da Serra. Além desses fóruns, a região comporta três Conselhos Regionais de Desenvolvimento - COREDEs: Vale do Jaguari, Central e Jacuí-Centro, criados pelo governo estadual com o objetivo de discutir políticas e ações voltadas ao desenvolvimento regional.

O governo federal dispõe para uma mesma região outros tipos de arranjos que conformam outros tipos de expectativas em torno de políticas territoriais, liderados por ministérios que também integram o Território da Cidadania. O Ministério da Integração Nacional estabeleceu, como unidade de gestão, o Fórum Mesosul10 e as Regiões de Faixa de Fronteira-Arco Sul11. O Ministério do Desenvolvimento

\footnotetext{
10 Instituído através da Política Nacional de Desenvolvimento Regional - PNDR, pelo decreto n. 6.047 de 22 de fevereiro de 2007.

11 O programa tem como objetivo principal promover o desenvolvimento da Faixa de Fronteira por meio de sua estruturação física, social e econômica, com ênfase na ativação das potencialidades locais e na articulação com outros países da América do Sul.
} 
Social estabeleceu o Consórcio de Segurança Alimentar e Desenvolvimento Local - CONSAD Centro. Como afirma Cazella (2012), o Estado tem papel fundamental na convergência do desenvolvimento territorial, e a descentralização das políticas é um marco fundamental para o Brasil. No entanto, ainda falta amadurecer a ação e planejar as políticas dos diferentes ministérios para os mesmos territórios de forma articulada, para que os recursos e os esforços encontrem sinergia.

Essa diversidade de organizações políticas presentes no território demonstra que o mesmo foi instituído sem a identificação dos recursos latentes já existentes. Assim, em vez de dar convergência às ações políticas, essa diversidade cria um paralelismo com outras políticas federais e estaduais (CAZELLA; BÚRICO, 2008). Essa falta de articulação entre os espaços políticos já existentes e as próprias estruturas do Governo Federal propostas para a região, de domínio de vários ministérios, demonstram que o território é mais um espaço e não "o espaço" de discussão das políticas públicas para o desenvolvimento do território.

Considerando essa heterogeneidade de espaços institucionais aqui apresentadas, cabe, ainda, ressaltar outras estratégias intermunicipais, como as divisões regionais das Secretarias Estaduais de Saúde e Educação, sendo possível observar uma multiplicidade de ações regionais. Sabendo que cada um desses conselhos conta com longas reuniões e suas próprias formas de articulação, em que é exigida a presença dos representantes municipais, é possível, talvez, indicar um dos motivos da participação não constante dos municípios da região no Colegiado Territorial. Essa confusão de diferentes políticas e espaços acaba criando um clima que não é propício para a sinergia de ações. Desse modo, alguns municípios, como também algumas organizações mais articuladas, acabam se privilegiando, ao mesmo tempo em que outros ficam alijados do processo. Entre os exemplos, chama atenção o montante dos recursos destinado para empreendimentos do município de Tupanciretã, que captou nove dos 62 contratos efetivados, totalizando $\mathrm{R} \$ 1.992 .158,53$. Desse modo, o município captou $20,6 \%$ do total de recursos descentralizados dentro do território no período entre 2003 e 2012.

Outra fragilidade do programa está relacionada com a incapacidade de dialogar com as demais políticas públicas, federais, 
estaduais ou municipais. Mesmo que o Estado apresente uma série de ações, tais como o PRONAF, Programa de Aquisição de Alimentos - PAA, Programa Nacional de Alimentação Escolar - PNAE e o Programa Mais Alimentos, pouco se alinham com o planejamento do PTDRS. Essa pulverização de recursos que o próprio Governo considera como parte do Programa do Território da Cidadania não consegue promover uma sinergia econômica, pouco dialogando com as potencialidades locais, e não tem conseguido incorporar conceitos importantes para estabelecer uma identidade territorial. Somente um ajuste nessas políticas e o estabelecimento de relações entre elas com as ações estaduais, que também acabam agindo isoladamente, poderiam promover um resultado mais efetivo enquanto política pública e, realmente, configurar-se em um pacto territorial.

Os municípios, da mesma maneira, pouco têm estabelecido conexões entre o que desejam para si e o que pretendem para o Território. Primeiro, porque, como destaca Arocena (2001), salvo exceções, os municípios não contam com equipes técnicas capazes de promover e levar adiante iniciativas concertadas de desenvolvimento. Como cada município tem sua participação assegurada no colegiado do Território, a representação é realizada, normalmente, pelo Secretário ou Técnicos da Secretaria de Agricultura. Os secretários são representantes políticos que reproduzem a lógica da afiliação partidária, o que não condiz, necessariamente, com pessoas com interesse e habilidade em discutir o desenvolvimento rural de acordo com a noção de desenvolvimento territorial. Os profissionais relacionados à Assistência Técnica e Extensão Rural - ATER, normalmente, pouco conhecem ou não visualizam uma perspectiva de desenvolvimento rural como um processo e acabam discutindo apenas questões pontuais sobre o meio rural. Desse modo, os projetos, muitas vezes, acabam refletindo iniciativas pontuais dos municípios, contrariando os pressupostos da política de desenvolvimento territorial. Nada impede que um projeto de um determinado grupo no município torne-se, posteriormente, em territorial, mas não se pode ignorar que a ausência da concertação de uma cooperação intermunicipal pode resultar na perda de oportunidades e recursos que poderiam ser utilizados para beneficiar mutuamente os municípios, como aponta Arocena (2001). Esses pontos contrastam com uma série de ações que, mesmo advindo da articulação 
do Território e do articulador, resguardada sua importância, deixam de dialogar com o enfoque territorial, parecendo atuar de forma unilateral ${ }^{12}$.

Nessa diversidade, fica difícil de existir um arcabouço institucional capaz de assegurar um pacto territorial e ações que levem ao empoderamento dos atores sociais em torno de ações a realizar. Por outro lado, a pactuação da sociedade em torno de objetivos comuns que perpassem a lógica do atendimento do interesse individual de organizações, partindo no sentido de construção de estratégias que mobilizem a região, é premissa fundamental para que o desenvolvimento territorial aconteça (ORTEGA; MENDONÇA, 2007).

No entanto, mesmo com esses limites apontados, os encontros entre os participantes da Plenária têm fortalecido uma rede de pessoas e de organizações, que começaram a pensar e a entender possibilidades diferentes de gerir as políticas públicas. As plenárias também têm se tornado um espaço de aprendizagem social entre as experiências desenvolvidas no território e que passam a ser conhecidas por todos os munícipios participantes. Ao mesmo tempo, a representatividade do governo federal e dos governos municipais em diversos momentos abre uma possibilidade de discussões em torno de outras ações que podem advir dessa concertação local. Essa questão dialoga com o que afirma Guanziroli (2012), ou seja, a necessidade de tempo e de uma trajetória para que a noção de desenvolvimento territorial seja aprendida pelos representantes sociais dos territórios.

Desse modo, reconhecendo que o Estado tem feito um esforço de construir políticas que buscam incluir o termo territorial, há de se reconhecer que o Território da Cidadania, como referência das políticas públicas, não tem conseguido integrar ações que são voltadas para um mesmo fim, apesar de estar gerando um aprendizado e uma mobilização importante na região. O desafio que se impõe para essa política é a real possibilidade desta assumir a condição de política nacional de desenvolvimento de territórios de fato, integrando as ações

12 Entre esses exemplos, encontram-se o mutirão para documentação da Mulher Trabalhadora Rural, voltado a desenvolver ações de expedição de documentos para as trabalhadoras rurais; o Projeto Arca das Letras, que buscava a implantação de biblioteca nas comunidades rurais; e a formação de técnicos e docentes do Instituto Federal Farroupilha Campus São Vicente do Sul na pedagogia da alternância, o qual gerou a iniciativa da Casa Familiar no Vale do Jaguari. 
e políticas públicas direcionadas para o território, criando sinergias e desenvolvendo possibilidades de mobilizar os ativos territoriais existentes.

\subsection{As limitações do Programa Território da Cidadania como Política Pública}

Além de uma série de questões já levantadas no decorrer do texto, busca-se evidenciar alguns elementos que parecem ser próprios do programa, em que se identifica alguns limites, conforme discriminados a seguir:

\section{$\checkmark \quad$ Público Beneficiário.}

A necessidade de extrapolar a discussão de desenvolvimento territorial para todos os setores da sociedade e não somente para assentados, agricultores familiares e quilombolas é essencial, conforme apontam Guanziroli (2012), Cazella e Búrigo (2008). Para Guanziroli (2012), a não inclusão da iniciativa privada, sob o argumento de que esta já teria se beneficiado, excessivamente, no passado, é limitada, pois significa não discutir com outras forças presentes no território, estabelecendo uma espécie de barreira ou "camisa de força" por parte daqueles que participam das plenárias. Ignorar a organização das sociedades atuais e determinadas características da estrutura social talvez represente desconsiderar a possibilidade de uma consciência coletiva na comunidade. Outra questão é a não otimização de recursos dispersos ou mal utilizados pelo território. Não se pode negar que, mesmo dentro dos grupos prioritários, existem atores melhor integrados do ponto de vista socioeconômico ou melhor informados.

Outro ponto que Delgado e Leite (2011) trazem para a discussão é a ausência de atores representativos da esfera social do mercado, que, em geral, os atores da sociedade civil têm dificuldades em aceitar e que, ao mesmo tempo, os primeiros têm pouco interesse em participar. Segundo os autores, não há como discutir desenvolvimento territorial sem considerar uma adequada combinação das esferas do Estado, da sociedade civil e do mercado na institucionalidade e nas dinâmicas territoriais.

Do mesmo modo, a visão de desenvolvimento, a partir do meio rural, não é suficiente para pensar uma estratégia de desenvolvimento. 
Segundo Abramovay (2000), Ortega e Mendonça (2007), o rural não pode continuar sendo visto como o local de sustentação da agricultura, pois as mudanças dinâmicas da sociedade, na atualidade, sugerem que muitos mercados e ações desenvolvidas no rural são capazes de atender às necessidades do meio urbano. José Eli da Veiga (2002) já alertava para isso no livro Cidades Imaginárias, pois o dinamismo de muitas regiões está na sinergia entre o meio rural e urbano, sendo que a visão de rural, como uma região residual do que não é urbano, dificulta a percepção das relações existentes entre o campo e a cidade.

Para que seja possível delinear estratégias capazes de ultrapassar as barreiras municipais, que sejam integradas e multisetoriais, o empoderamento deve perpassar por todos os atores sociais das mais diversas instituições. Essa necessidade converge com o observado no território da Cidadania Central, pois o debate não chega até as bases, e muitas organizações sequer ficam sabendo da existência desse fórum de debates.

\section{$\checkmark \quad$ Descentralização somente para Entidades públicas}

Arocena (2001) aponta, como um dos desafios para o desenvolvimento territorial na América Latina, a descentralização de recursos para o apoio técnico e financeiro para as inversões produtivas. É necessário desenvolver mecanismos para que a descentralização de recursos da união realmente mobilize as capacidades produtivas instaladas no território ou o potencial produtivo ainda não explorado. Os recursos devem ser descentralizados para criar bens públicos, no entanto, não necessariamente, só para instituições públicas. O acórdão do Tribunal de Contas da União de n. 1.564/2011 destaca o investimento público em instituições privadas e da sociedade, obrigando os Ministérios a recolher bens que estão em posse de organizações não governamentais. Esse instrumento legal dificulta sobremaneira 0 financiamento público de empreendimentos, mesmo que coletivos, e acaba centralizando, nas Prefeituras Municipais, a condição de discutir ou não a política de desenvolvimento territorial.

\section{$\checkmark$ Afirmação enquanto política pública}

A incerteza como política pública talvez seja um dos maiores limitantes do Território da Cidadania, pois apresenta fragilidades em assumir o caráter de espaço prioritário para a discussão de ações territoriais e não garante continuidade de suas ações. $O$ espaço tem sido 
utilizado pelo governo federal como espaço prioritário para a descentralização dos recursos, beneficiando tanto instituições participantes como não participantes das atividades do Colegiado Territorial. Entre os exemplos, estão a distribuição de uma retroescravadeira pelo Programa de Aceleração do Crescimento - PAC 2 e de um veículo de transporte escolar pelo Fundo Nacional de Desenvolvimento da Educação - FNDE, contemplando 30 municípios em 2011 , que se candidatavam ao recurso por meio de uma carta consulta. Para ações desse tipo, não há necessidade de um Território, pois, dessa forma, esse espaço torna-se apenas uma roupagem para as pretensões do governo federal.

A descontinuidade e limitação da execução financeira são outras fragilidades do programa. Buscando os projetos financiados no decorrer dos anos de implantação do programa, percebe-se um acréscimo contínuo nos recursos de 2003 (em 2003, foram destinados $\mathrm{R} \$ 312.738,83$ ) a 2010 (em 2010 , foram oito contratos no valor total de $\mathrm{R} \$ 1.422 .105,52$ ) e um decréscimo brusco em 2011 (em 2011, foram apenas de $R \$ 150.000,00)$. Para o ano de 2012 , não foram previstos recursos de descentralização, ficando a busca de recursos sob responsabilidade do próprio Colegiado. Nesse sentido, foram captadas duas emendas parlamentares, no valor total de $\mathrm{R} \$ 2.906 .000,00$ para serem investidos em 11 municípios, beneficiando 2.710 famílias, sendo deliberado como seria utilizado em plenárias do Território. Essas indefinições acabam fragilizando ainda mais a organização já estabelecida, e a falta de garantia do recurso pode desmobilizar os agentes que participavam ativamente do processo.

Outra questão relacionada à descontinuidade de ações dentro do Território é o número de ações que começam e não terminam. No ano de 2008, foi desenvolvido um estudo sobre a cadeia produtiva da apicultura, mas as ações desencadeadas a partir daí não foram executadas em virtude de contingenciamento financeiro do MDA. Em 2010, foi contratada consultoria para estudos territoriais relativos às cadeias da fruticultura e piscicultura, mas também sem continuidade nas amarras com os projetos locais. Em 2011, a Emater/RS-Ascar, como parte do programa de ATER Territorial, mediante um diagnóstico, fez amplo levantamento de dados do território. No entanto, parece que o trabalho encerrou-se no diagnóstico. O Estado não se pronuncia em 
favor da continuidade, e os municípios não têm políticas alinhadas com essas demandas.

Ortega e Mendonça (2007) alertam para a dificuldade em romper com algumas práticas tradicionais existentes nas políticas públicas brasileiras - políticas fragmentadas e setoriais; pulverização e competição entre os setores da administração pública; natureza clientelista e assistencialista, mas que atestam as diferentes concepções do papel do Estado nos processos de desenvolvimento territorial. Por outro lado, a ânsia de promoção de políticas compensatórias para públicos alijados do desenvolvimento deixa de resgatar outros aspectos essenciais para ações empoderadoras de públicos vulneráveis socialmente nos territórios.

\section{Considerações finais}

A política de desenvolvimento territorial brasileira ainda está em estágio inicial de organização. São inegáveis os desafios e as dimensões que essa noção contempla como espaço de aprendizagem, empoderamento e comprometimento dos poderes públicos locais e, principalmente, da sociedade com o desenvolvimento.

Pode-se verificar que, em relação às peculiaridades do território da cidadania central do RS, o seu tamanho e toda a sua diversidade são limitantes para a aplicação da política pública. Essa diversidade, aliada à forma tradicional de gerir os municípios e suas políticas e à forma de participação de cada componente, dificulta a construção de projetos que perpassem o território, ficando concentrada em ações locais. Os esforços realizados, tais como a definição de microrregiões, parecem não estar resultando em ações colaborativas entre os municípios integrantes. Mesmo assim, pode-se observar que, nessa diversidade de situações, algumas ações colaborativas entre as instituições participantes do território têm sido desencadeadas e significam melhoria nas capacidades instaladas e no clima social da comunidade, em um sinal claro de aumento de capital social. As iniciativas desse porte, fortalecidas por uma política pública, necessitam ser aprimoradas, pois representam importantes espaços de reunião de agentes públicos e da sociedade civil, de discussão e de mobilização do território. Nesse sentido, mesmo que pretensa, a missão de unificar as 
políticas públicas em torno de um território determinado, bem como a de corrigir as mazelas históricas recorrentes no meio rural, por meio do Território da Cidadania, representa uma superação no pensar das políticas públicas brasileiras.

A excessiva fragmentação em relação ao público beneficiário, setores e fóruns de descentralização tem levado a uma verdadeira miscelânea de ações pretensamente territoriais, ocasionando a dificuldade de se construírem estratégias territoriais unificadas, convergentes e sinérgicas, perdendo-se localmente em iniciativas individuais que pouco dialogam entre si. Da mesma forma, são necessárias adequações jurídicas e institucionais na política, para que a mesma não fique condicionada às inclinações e humores de prefeitos e organizações bem intencionadas para o desenvolvimento das experiências. A compreensão e a implementação da noção de desenvolvimento territorial e da promoção do capital social não ocorrem, simplesmente, pela aplicação de uma política pública, é necessário um tempo para que esses significados sejam entendidos pelos atores sociais. Essa é a razão pela qual ganha importância a presença de comitês de articulação em cada território, ativando recursos, mobilizando pessoas, socializando informações e promovendo as comunidades no exercício de sua própria cidadania. Os articuladores têm papel preponderante na preparação e realização de atividades formativas, para que os atores sociais apropriem-se desses espaços e fortaleçam-se as condições institucionais.

A avaliação crítica das possibilidades e limites tomados por este texto é uma visão do Território Central do RS, mas considerando, também, o que tem acontecido em outras realidades. Pode-se concluir que, mesmo diante das dificuldades, a política pública tem conseguido promover mudanças significativas na forma de mobilizar os atores sociais, promover discussões e definir questões propositivas para o território. Porém, as evidências demonstradas pelo Estado e relatadas neste artigo, em se retirar da política e deixar sob a guarda do próprio Território a construção dos rumos a seguir, podem ser precipitadas. $\mathrm{O}$ tempo de existência da política pública e a forma pela qual vem sendo estabelecida não são suficientes para ela se consolidar, gerar impactos produtivos, garantia de recursos para investimento e formação dos recursos humanos capazes de estabelecer a própria governança local. 
Diante das peculiaridades do Território, pode-se inferir que ainda não existe um protagonismo social dos atores que seja capaz de consolidar uma nova institucionalidade territorial e que seja capaz de dar continuidade na política. A necessidade é aprimorar a política pública, de modo a possibilitar que se dê conta de toda a diversidade existente no Território da Cidadania Central do RS e, também, em outros territórios existentes no Brasil.

\section{REFERÊNCIAS}

ABRAMOVAY, R. O capital social dos territórios: repensando o desenvolvimento rural. Economia Aplicada, v. 4, n. 2, p. 379-397, abr./jun. 2000.

ABRAMOVAY, R. Para uma teoria dos estudos territoriais. In: ORTEGA, A. C.; ALMEIDA FILHO, N. (Org.). Desenvolvimento territorial, segurança alimentar e economia solidária. Campinas: Alínea, , v.1, p. 19-38, 2007.

AROCENA, J. El desarrollo local: un desafio contemporáneo. Montevidéo: Taurus/Universidad Católica. 1993.

BONNAL, P., CAZELLA, A., DELGADO, N. G. Subsídios metodológicos ao estudo do desenvolvimento territorial rural. In.: LEITE, S. P. e DELGADO, N. G. (Org.) Políticas públicas, atores sociais e desenvolvimento territorial no Brasil. v.14 (Série desenvolvimento rural sustentável), p.35-60. Brasília: IICA, 2011.

BRASIL. Decreto n. ${ }^{\circ} 4.854$ de 8 de outubro de 2003. Dispõe sobre a composição, estruturação, competências e funcionamento do Conselho Nacional de Desenvolvimento Rural Sustentável - CONDRAF, e dá outras providências. Brasília, DF, 8 out. 2003. Disponível em:

$<\quad$ http://www.planalto.gov.br/ccivil_03/decreto/2003/d4854.htm>. Acesso em: 15 out. 2012

CAZELLA, A. A. As Bases sociopolíticas do Desenvolvimento territorial: uma análise a partir da experiência francesa. In: FROEHLICH, J. M. (org.) 
Desenvolvimento Territorial: produção, identidade e consumo. Ijuí: Editora Unijuí, p. 15-52, 2012.

CAZELLA, A. A.; BURIGO, F. L. O desenvolvimento territorial no Planalto Catarinense: o difícil caminho da intersetorialidade. Revista Extensão Rural. Santa Maria, ano 15, jan. - jun., p. 05-30, 2008.

COMISSÃO EUROPEIA. $A$ abordagem Leader: Um guia básico. Luxemburgo: Serviço das Publicações Oficiais das Comunidades Europeias, 2006.

DELGADO, N. G., LEITE, S. P. Políticas de Desenvolvimento Territorial no Meio Rural Brasileiro: Novas Institucionalidades e Protagonismo dos Atores. DADOS - Revista de Ciências Sociais. Rio de Janeiro, v. 54, n. 2, p. $431-473.2011$.

ECHEVERRI. R. Emergência e evolução do programa de desenvolvimento sustentável dos Territórios Rurais e nos Territórios da Cidadania. In.: FAVARETO. A. (Org.) Políticas de desenvolvimento territorial rural no Brasil: avanços e desafios. Brasília: IICA, (Série Desenvolvimento Rural Sustentável; v.12). p. $81-112,2010$.

FAVARETO. A. Tendências contemporâneas dos estudos e políticas sobre o desenvolvimento territorial. In: FAVARETO. A. (Org.) Políticas de desenvolvimento territorial rural no Brasil: avanços e desafios. Brasília: IICA, (Série Desenvolvimento Rural Sustentável; v.12). p. 15 - 46, 2010.

GUANZIROLI, C. E. Desenvolvimento territorial rural no Brasil: uma polêmica. In: FROEHLICH, J. M. (org.) Desenvolvimento Territorial: produção, identidade e consumo. Ijuí: Editora Unijuí, p. 203-224, 2012.

GUERRERO, M. G. La Red Social como elemento Clave del Desarrollo Local. Lisboa: Sociedade Portuguesa de Estudos Rurais, 1996.

HARVEY, D. Espaços de esperança. 4 ed. São Paulo: Edições Loyola, 2011. 
HESPANHOL, R. A. de M. PRONAF Infra-estrutura e serviços municipais e associações de produtores em municípios selecionados da região de presidente prudente, estado de São Paulo. Informações Econômicas, v. 36, n. 5, p. 15-24, maio. 2006.

JIMENEZ, E. M. Nuevos enfoques teóricos, evolución de las políticas regionales e impacto territorial de la globalización. Santiago/Chile: Nações Unidas, 2002.

NEUMANN, P. S. O processo de diferenciação econômica do espaço rural e dos agricultores na região central do RS. In.: FROEHLICH, J.M e DIESEL, V. (Org.). Espaço Rural e Desenvolvimento Regional: estudos a partir da região central do RS. Ijuí: Editora Unijuí, p. 55 - 103, 2004.

ORTEGA, A. C., MENDONÇA, N. C. Estratégias de desenvolvimento territorial rural no Brasil: continuidades e rupturas. In: ORTEGA, A. C.; ALMEIDA FILHO, N. (Org.). Desenvolvimento territorial, segurança alimentar e economia solidária. Campinas: Alínea, v.1, p. 94-121, 2007.

PECQUEUR, B. O desenvolvimento territorial: uma nova abordagem dos processos de desenvolvimento para as economias do Sul. Raízes, v. 24, n. 1 e 2, p.10-22, jan-dez. 2005.

PUTNAM, R. D. Comunidade e Democracia: A Experiência da Itália Moderna. Rio de Janeiro: FGV, 2003.

REIS, J. Uma epistemologia do território. Estudos Sociedade $e$ Agricultura, Rio de Janeiro, v. 13, n. 1. 2005: Disponível em:< http://r1.ufrrj.br/esa/art/200504-051-074.pdf>. Acesso em: 15 out. 2012.

SUMPSI, J. M. Desarollo rural con enfoque territorial: diferencias y semejanzas de las experiencias de La Unión Europea y America Latina. In: In: ORTEGA, A. C.; ALMEIDA FILHO, N. (Org.). Desenvolvimento territorial, segurança alimentar e economia solidária. Campinas: Alínea, v.1, p. $19-38,2007$. 
VEIGA, J. E. Cidades Imaginárias: o Brasil é menos urbano do que se calcula. Campinas: Autores Associados, 2002.. 
Submetido em 03/11/2014

Aprovado em 24/03/2016

Sobre os autores

Tatiana Aparecida Balem

Doutora em Extensão Rural, Mestre em Extensão Rural, Engenheira Agrônoma,

Docente no Instituto de Educação, Ciência e Tecnologia Farroupilha campus Júlio de Castilhos.

E-mail: tatianabalem@yahoo.com.br

\section{Gustavo Pinto da Silva}

Doutor em Extensão Rural, Mestre em Extensão Rural, Zootecnista,

Docente na Universidade Federal de Santa Maria.

E-mail: gustavo.pinto@politecnico.ufsm.br

\section{José Marcos Froehlich}

Pós-Doutor em Antropologia Social, Doutor em Ciências Sociais, Mestre em Sociologia; Graduação em Agronomia. Docente na Universidade Federal de Santa Maria. .

E-mail:jmarcos.froehlich@gmail.com 